\title{
Trends in food and beverage sources among US children and adolescents: 1989-2010
}

\author{
Meghan M. Slining, PhD, Kevin Mathias, MS, and Barry M. Popkin, PhD ${ }^{1}$ \\ ${ }^{1}$ University of North Carolina at Chapel Hill, Department of Nutrition, Chapel Hill, NC
}

\section{Abstract}

Despite the historical rise and recent plateau of child overweight and obesity, levels remain exceedingly high. To understand these trends and identify targets for intervention it is important to examine concomitant trends in children's diets. The objective of the current analysis was to describe 21-year trends in total energy intake and the major food and beverage sources of energy among 2- to 18- year olds in the United States (US). Six nationally representative surveys were examined in 2012, the Continuing Survey of Food Intakes by Individuals Surveys (1989-1991 and 1994-1996, 1998) and the National Health and Nutrition Examination Surveys (2003-2004, 2005-2006, 2007-2008 and 2009-2010). Total energy intake among US children and adolescents rose considerably from 1989 to 2004, and subsequently declined through 2010. Seven sources were consistently major contributors across all time points: sugar-sweetened beverages (SSB), pizza, high fat milk, grain-based desserts, breads, pasta dishes and savory snacks. Intakes of high fat milk, meats and processed meat products, ready-to-eat cereals, burgers, fried potatoes, fruit juice and vegetables decreased from 1989-2010 while intakes of low fat milk, poultry, sweet snacks and candies and tortilla and corn-based dishes increased linearly over the 21-year period. Significant non-linear time trends were observed with recent decreases in intakes of SSBs, pizza, pasta dishes, breads and rolls and savory snacks and recent increases in intake of fruit. Energy intakes of US children began to decline in 2003-2004 and continued to decline through 20092010. However among preschool children (2-5 years old) and children from low income families, total energy intakes in 2009-2010 still remained significantly higher than in 1989-1991.

\section{INTRODUCTION}

Despite the historical rise and recent plateau of child overweight and obesity, levels remain exceedingly high and the consequences for all overweight and obese youth over their lifetime remain very important. ${ }^{1-5}$ To understand these trends and identify targets for intervention it is important to examine concomitant trends in children's diets. An extensive body of literature has provided critical insight into changes in overall food and nutrient intakes among US children and adolescents; ${ }^{6-14}$ however, the majority of this work examines diets prior to the mid-2000's. While our research group has studied recent trends in eating behaviors that may in part explain changes in overall dietary intakes (e.g., increases

(C) 2013 Academy of Nutrition and Dietetics. Published by Elsevier Inc. All rights reserved.

Corresponding author: Meghan Slining Ph.D. M.P.H., Research Assistant Professor, Department of Nutrition, Gillings School of Global Public Health, University of North Carolina at Chapel Hill, Mailing Address: University Square, CB\#8120, 123 West Franklin Street, Chapel Hill, NC 27516-3997, Phone: 919-962-6115, Fax: 919-966-9159, slining @unc.edu.

Publisher's Disclaimer: This is a PDF file of an unedited manuscript that has been accepted for publication. As a service to our customers we are providing this early version of the manuscript. The manuscript will undergo copyediting, typesetting, and review of the resulting proof before it is published in its final citable form. Please note that during the production process errors may be discovered which could affect the content, and all legal disclaimers that apply to the journal pertain. 
in portion sizes, snacking, eating occasions and the proportion of calories consumed away from home ${ }^{9,15-18}$ ), we have not examined long-term 20-year shifts in overall child diets.

The current study was conducted to identify changes in total energy intakes and the major sources of energy intake among US children and adolescents over the time period corresponding to the earlier rise and recent plateau of child obesity. ${ }^{2,5}$ Using the most recent nationally representative dietary intake data, this study examined the long-term shifts in child diets over the last two decades that may have implications for the development of dietrelated diseases.

\section{METHODS}

\section{Data Sources and Samples}

This study examined cross-sectional data on 2-18 year olds from six nationally representative surveys of food intake in the US: the Continuing Survey of Food Intakes by Individuals Surveys (CSFII) of 1989-1991 (CSFII 89, n=4,008) and 1994-1996, 1998 (CSFII 96, n=9,008) and the What We Eat in America, National Health and Nutrition Examination Surveys (WWEIA-NHANES) 2003-2004 $(\mathrm{n}=3,554), 2005-2006(\mathrm{n}=3,778)$, 2007-2008 $(n=2,966)$, and 2009-2010 $(n=3,124)$. Detailed information about the operation of each survey and sampling design has been published elsewhere. ${ }^{19-21}$ As described below, each survey has utilized updated versions of the same USDA food composition table, thereby enhancing their comparability.

\section{Dietary Intake}

CSFII 1989-91-Information on dietary intake was collected on three consecutive days using an interviewer-administered 1-day dietary recall and a self-administered 2-day dietary record. The main meal planner/preparer within a household reported for children less than 12 years of age.

CSFII 1994-1996 and 1998-Information on dietary intake was collected using interviewer-administered 1-day dietary recalls on two nonconsecutive days. The 1-day recall was modified to include multiple passes through the list of all foods and beverages. The main meal planner/preparer within a household reported for children less than 12 years of age.

WWEIA-NHANES 2003-04, 2005-06, 2007-08, and 2009-10-Trained interviewers conducted one in-person 24-h dietary recall and one subsequent 24-h dietary recall over the telephone utilizing the USDA's Automated Multiple-Pass Method (AMPM). Survey participants aged 12 years and older completed the dietary interview on their own, proxyassisted interviews were conducted with children aged 6 to 11 years, and proxy respondents reported for children younger than five years of age. ${ }^{22}$

Dietary intake data collected by the USDA in the CSFII and by the USDA and the National Center for Health Statistics in NHANES were designed to provide nationally representative information on American's food and nutrient intakes at the time of the survey. In order to examine trends over time from surveys with different numbers of days of dietary information and different collection methods, we utilize only the first day's data (a single 24-h dietary recall) collected from each individual.

\section{Food composition information}

Dietary intake data from each survey period were linked to a USDA food composition database derived from the corresponding time period to estimate nutrient and total energy 
intake. Files for analyzing food and nutrient intakes have been updated over several decades of food surveys. ${ }^{23}$ For CSFII 1989-91 and 1994-98 data were used from the Survey Nutrient Database. ${ }^{24}$ In 2004, the files were incorporated into one database, the Food and Nutrient Database for Dietary Studies (FNDDS), for processing WWEIA. FNDDS versions 2.0, 3.0, 4.1 and 5.0 were used for the WWEIA-NHANES 2003-04, 2005-06, 2007-08 and 2009-2010 surveys, respectively. ${ }^{25-28}$ Every version of the nutrient database is updated to reflect the US food supply by incorporating new foods based on what is reported in the survey, updating existing entries, and new and updated nutrients provided in new versions of Standard Reference. As a result, the total number of food codes has increased with subsequent database releases from 6,698 food codes in 1989-91 to 7,253 food codes in 2009-10. ${ }^{29}$ Each nutrient database was derived from the USDA Nutrient Data Base for Standard Reference, versions 10, 11, 18, 20, 22 and 24..$^{29-33}$

\section{Food and beverage groupings}

The food grouping system used for this study was developed by our team to examine a variety of research questions. Originating with the nine USDA food groupings, groups were systematically disaggregated based on nutrient composition, critical dietary behaviors and similarities in consumption patterns. In addition, select popular foods (e.g. pizza and hamburgers/cheeseburgers) were classified as their own group. A total of 41 mutually exclusive food groups and 12 beverages groups were created. Eight-digit food/beverage codes assigned by the USDA to each item were linked to a designated food group to ensure that foods and beverages were consistently placed in the same group across the six times periods used in this study. See Appendix 1 for a complete list of food and beverage groups.

With advances in dietary data collection and coding methods, the flexibility and specificity of intake data has improved over time. During the collection and coding of dietary recall data, individual food codes may be linked together using "combination" codes which allow combining the nutritional information of individual foods that are consumed together at an eating occasion. For example, sugar in coffee or food mixtures, such as a homemade burrito, that is reported as separate ingredients: beans, cheese, lettuce and salsa, can be combined into single food items, though not all aggregated foods are captured by this coding scheme. In order to describe consumption trends in comparable food and beverage groupings over time, select combination codes relevant to the current research (specifically, beverages, corn and tortilla products, soups, and ice cream with additions) were incorporated. For each of these examples, the nutrient content of every individual item was summed into one combined food or beverage.

\section{Statistical analysis}

Data analyses were conducted in 2012 using Stata (version 11.0, 2009, StataCorp, College Station, TX). Dietary recalls (Day 1 only) for all 2-18 year olds with data deemed reliable by the study developers were included in this analysis. In order for estimates to be representative of the children and adolescents living in the US, analytic weights were assigned to survey respondents who participated in the dietary recall and account for differential probabilities of selection and participation. Mean daily energy intakes were estimated for each survey time period. Differences in energy intake were examined by sex, age $(2-5,6-11,12-18)$, race/ethnicity (non-Hispanic whites, non-Hispanic blacks and Mexican Americans), family income based on the federal poverty income ratio (gross) (using three poverty income ratio categories: $₫ 30 \%$ of poverty income ratio, $131-185 \%$ and $>185 \%$, and education level of household reference person ( $<$ high school, high school or equivalent degree, some college). To identify the major sources of energy intake, mean intakes of energy obtained from each food and beverage category were estimated and ranked for each survey year. To calculate the per capita percent contribution of a particular food or 
beverage group to total daily intake, for each respondent, the energy consumed from a given food group was divided by their total daily energy consumed. Differences were considered statistically significant at the $p<0.05$ level after Bonferonni correction.

A trend analysis for total energy intake and energy intake from food and beverage sources was conducted by testing the significance of time when modeled as linear, quadratic and higher order terms in separate multivariate regression models. All models examining time trends included the following confounders: age, race/ethnicity, family income and education level of household reference. Testing the statistical significance of the coefficients for the higher order terms was performed using Wald $\mathrm{F}$ tests $(p<0.05)$.

\section{RESULTS AND DISCUSSION}

Demographic patterns in the US have shifted over a 20-year period (Table 1), the greatest of which were a 13 percentage point decrease in the proportion of non-Hispanic Whites, a 9 percentage point decrease in the proportion of adults with a high school or equivalent degree and a 14 percentage point decrease in the proportion of children from higher income households between 1989-1991 and 2009-2010.

\section{0-year time trends in energy intake}

A significant non-linear time trend in per capita daily energy intake from 1989-2010 was observed among all subpopulations except middle income children (Table 2). From 19892004 , there was a significant, monotonic increase in the per capita total daily energy intake for US 2-18 year olds. The largest increases were among preschool children (2-5 y old) $(+305 \mathrm{kcal})$, Mexican Americans $(+428 \mathrm{kcal})$, children in low income families $(+437 \mathrm{kcal})$ and children with a household reference with high school or equivalent education $(+387$ kcal) (Table 2). Conversely, total energy intake decreased across the time period of 20032004 to 2007-2008 and remained stable through 2009-2010. For most US children, the decline brought energy intakes down to levels comparable with those observed in 1989-91. Only preschool children ( $2-5$ y old), and children in low income families had higher total energy intakes in 2009-2010 as compared to 1989-91 (Table 2).

The increases we observed from the late 1980's to the mid 2000's coincide with earlier nationally representative literature documenting increases in total energy intakes from 1971$2006^{6,18,34}$ as well as increases in portion sizes, snacking, eating occasions and the proportion of calories consumed away from home by US children and adolescents. ${ }^{9}, 15-18$ However, in contrast to these findings, Kant and Graubard observed no change in total energy intakes among US children and adolescents from 1988-2008. ${ }^{9}$

Plausible explanations for these differences exist. While Kant and Graubard utilized NHANES data from 1988-2002, our study utilized CSFII data over the same time periods to maintain consistency in food composition data as well as other USDA handling, processing and coding of survey data. Furthermore, Kant and Graubard combined surveys from 20032008, thus masking the large decreases in energy intakes we observed over these time periods.

The current study expands our understanding of the long-term trends in child diets by documenting a post-2004 marked downward shift in reported energy intakes. By 20092010, the total energy intakes of most children and adolescents in the US had declined to levels observed prior to the sharp rise in obesity in the 1980's. While these encouraging findings support continued obesity prevention efforts aimed at improving child diet, we note that not all groups experienced the same declines. It may be that more intensive interventions are needed among preschool children (2-5 y old) and children from low 
income families whose total energy intakes in 2009-2010 still remained significantly higher than in 1989-91.

\section{0-year time trends in food and beverage sources of energy intake}

Table 3 lists the 13 food and beverage categories that were ranked within the top 10 sources of energy intake across all six survey periods. Seven sources were consistently major contributors (within the top ten sources) across all time points: sugar-sweetened beverages (SSB), pizza, high fat milk, grain-based desserts, breads, pasta dishes and savory snacks. Per capita intakes of high fat milk, frankfurters, sausages, luncheon meats and other processed meat products, ready-to-eat (RTE) cereals and meats decreased from 1989 to 2010, while per capita intakes of tortilla and corn-based dishes increased over the 21-year period. Significant non-linear time trends were observed for SSBs, pizza, breads and rolls, savory snacks, poultry and sweet snacks and candies. Pizza and SSB intake trends were most similar to those observed for total energy intake with increases from 1989-2004, followed by subsequent declines. Pizza showed the largest initial increase by doubling from $65 \mathrm{kcal} / \mathrm{d}$ in $1989-91$ to $141 \mathrm{kcal} / \mathrm{d}$ in $2003-2004$ followed by more modest declines to $105 \mathrm{kcal} / \mathrm{d}$ by 2009-10. Intakes of savory snacks, poultry and sweet snacks and candies showed more modest increases from 1989 through the 2003-2006 periods and remained stable from 2003 through 2010. Mean intakes of specific foods contributing at least 2\% energy (absolute intake and percent contribution to daily energy intakes) are presented in Appendix 2. Per capita intakes of burgers, fried potatoes, fruit juice and vegetables decreased from 19892010 , whereas, per capita intakes of low fat milk, quick breads and sandwiches increased from 1989-2010. Intakes of fruit and rice dishes decreased from 1989-91 through the 20032006 periods and subsequently increased to 2009-2010.

These findings are similar to other studies examining the sources of intake among US children and adolescents from the late 1960's through the early 2000's 6, 7, 12-14, 35, 36 which show increases in intakes of low fat milks, sweet snacks and candies and decreases in intakes of high fat milk, breads and meats through early 2003-2004. We demonstrate subsequent persistence of these trends through 2010. For SSB, while the current findings show similar increases in intake through 2003-2004 a subsequent decrease in intakes of SSB was observed through 2009-2010. The SSB trends are also consistent with recent data demonstrating steady decreases in the availability of SBBs in public elementary schools since $2006-2007 .{ }^{37}$

Reducing excessive energy intake, especially from foods and beverages that provide empty calories from solid fats and added sugars, and improving dietary quality are major goals in the US. ${ }^{38-41}$ Eight of the thirteen major contributors to energy intakes across all six survey periods (pizza, high fat milks, SSB, RTE cereals, sweet snacks and candies, grain-based desserts and (frankfurters, sausages, luncheon meats and other processed meat products)) represent top dietary sources of SoFAS. ${ }^{42}$ Indications of potential improvements in US child diet consistent with recommendations from the Dietary Guidelines include recent increased intake of fruit and decreased intake of pizza, SSB, high fat milks, and frankfurters, sausages and luncheon meats, burgers and fried potatoes. ${ }^{38}$

\section{Limitations}

Several cautions are noted to aid in the interpretation of our findings. Across surveys, there were differences in the population composition which may explain some of the observed changes. Dietary intake assessment methods and food composition information have significantly improved over time. Although data presented are based on the first day 24-h recall from all surveys, the recall methodology was modified to include multiple passes through the list of foods and beverages in the CSFII 1994-96, 98 and to include the USDA's 
AMPM in all subsequent WWEIA-NHANES surveys. While validation studies of the AMPM have not been conducted in children validation studies in adults have shown the AMPM improved completeness of the recall. ${ }^{43}$ As such, it is possible that the observed increases in energy intake from 1989-2004 are an artifact of the more complete capture of the data.

Despite improvements in dietary assessments methods, research suggests that collecting reliable and accurate dietary data from children and adolescents remains difficult. ${ }^{44,45}$ Underreporting of intake has been associated with factors such as age, race/ethnicity and body weight status, ${ }^{45-48}$ and underreporting appears to be greatest among unhealthy foods or foods perceived to be related to obesity. ${ }^{48-50}$ While we note that available dietary intake methods are considered to be capable of providing unbiased estimates of energy intake at the population level, it remains possible that with heightened awareness of pediatric overweight and obesity, the observed decreases from 2005-2006 onwards are a result of the population's differential underreporting of dietary behaviors that may be perceived negatively though other research from our group suggest these changes are real. ${ }^{51}$

\section{Conclusions}

Despite the historical rise and recent plateau of child overweight and obesity, levels remain exceedingly high as are the resultant health and social consequences for these children over their lifetime. The current study documents a recent downward shift in reported energy intakes among US children and adolescents to levels observed prior to the sharp rise in obesity in the 1980's. While these encouraging findings support continued obesity prevention efforts aimed at improving child diet, we note that not all groups experienced the same declines. It may be that more intensive interventions are needed among preschool children (2-5 y old) and children from low income families whose total energy intakes in 2009-2010 still remained significantly higher than in 1989-91.

\section{Acknowledgments}

We thank the Robert Wood Johnson Foundation (Grant 67506) and the National Institutes of Health (R01 HL104580 and CPC 5 R24 HD050924) for financial support. We also thank Dr. Phil Bardsley for exception assistance with the data management and programming and Ms. Frances L. Dancy for administrative assistance.

\section{References}

1. Eaton DK, et al. Youth risk behavior surveillance--United States, 2007. MMWR Surveill Summ. 2008; 57(4):1-131. [PubMed: 18528314]

2. Ogden CL, et al. Prevalence of obesity and trends in body mass index among US children and adolescents, 1999-2010. JAMA. 2012; 307(5):483-90. [PubMed: 22253364]

3. Ogden CL, et al. Prevalence of high body mass index in US children and adolescents, 2007-2008. JAMA: the journal of the American Medical Association. 2010; 303(3):242-9. [PubMed: 20071470]

4. Centers for Disease, C. and Prevention. Obesity prevalence among low-income, preschool-aged children - United States, 1998-2008. MMWR Morb Mortal Wkly Rep. 2009; 58(28):769-73. [PubMed: 19629026]

5. Pan L, et al. Trends in the prevalence of extreme obesity among us preschool-aged children living in low-income families, 1998-2010. JAMA: The Journal of the American Medical Association. 2012; 308(24):2563-2565. [PubMed: 23268509]

6. Briefel RR, Johnson CL. Secular trends in dietary intake in the United States. Annu Rev Nutr. 2004; 24:401-31. [PubMed: 15189126]

7. Cavadini C, Siega-Riz AM, Popkin BM. US adolescent food intake trends from 1965 to 1996 . Arch Dis Child. 2000; 83(1):18-24. [PubMed: 10868993] 
8. Herzog, editor. U.S. Department of Agriculture, Food and Nutrition Service, Office of Analysis, Nutrition and Evaluation. Changes in Children's Diets: 1989-1991 to 1994-1996, CN-01-CD2, Phil Gleason and Carol Suitor. Project Officer. Alexandria, VA: 2001.

9. Kant AK, Graubard BI. 20-Year trends in dietary and meal behaviors were similar in U.S. children and adolescents of different race/ethnicity. The Journal of Nutrition. 141(10):1880-8. [PubMed: 21865567]

10. Nielsen SJ, Siega-Riz AM, Popkin BM. Trends in energy intake in U.S. between 1977 and 1996: similar shifts seen across age groups. Obes Res. 2002; 10(5):370-8. [PubMed: 12006636]

11. Sebastian RS, et al. Trends in the food intakes of children 1977-2002. Consumer Interests Annual. 2006; 52:433-434.

12. Wilkinson Enns C, Mickle SJ, Goldman JD. Trends in food and nutrient intakes by children in the united states. Family Economics and Nutrition Reviews. 2002; 14(2):56-68.

13. Wilkinson Enns C, Mickle SJ, Goldman JD. Trends in food and nutrient intakes by adolescents in the United States. Family Economics and Nutrition Reviews. 2003; 15(2):15-27.

14. Williams, C. Resource 1: Children's dietary intakes. Supplemental information related to Report of the Dietary Guidelines Advisory Committee on the Dietary Guidelines for Americans. 2010.

15. Piernas C, Popkin BM. Food portion patterns and trends among U.S. children and the relationship to total eating occasion size, 1977-2006. The Journal of Nutrition. 2011; 141(6):1159-64. [PubMed: 21525258]

16. Piernas C, Popkin BM. Increased portion sizes from energy-dense foods affect total energy intake at eating occasions in US children and adolescents: patterns and trends by age group and sociodemographic characteristics, 1977-2006. Am J Clin Nutr. 2011

17. Piernas C, Popkin BM. Trends in snacking among U.S. children. Health Aff (Millwood). 2010; 29(3):398-404. [PubMed: 20194979]

18. Poti JM, Popkin BM. Trends in energy intake among US children by eating location and food source, 1977-2006. J Am Diet Assoc. 2011; 111(8):1156-64. [PubMed: 21802561]

19. NCHS, CDC, and USDHHS. National Health and Nutrition Examination Survey Data. Hyattsville, MD: 2003-2004.

20. NCHS, CDC, and USDHHS. National Health and Nutrition Examination Survey Data. Hyattsville, MD: 2007-2008.

21. NCHS, CDC, and USDHHS. National Health and Nutrition Examination Survey Data. Hyattsville, MD: 2005-2006.

22. NCHS. Dietary Interview, NHANES 2003-2004. Public Data General Release File Documentation. Oct 21. 2010 ]; Available from: http://www.cdc.gov/nchs/nhanes/ about_nhanes.htm

23. Bodner J, Perloff B. Databases for analyzing dietary data -- the latest word from What We Eat in America. Journal of Food Composition and Analysis. 2003; 16(3):347-358.

24. USDA and ARS. Continuing Survey of Food Intakes by Individuals 1994-96, 1998 (CSFII 199496, 1998).

25. USDA. Food and Nutrient Database for Dietary Studies, 2.0. A.R.S. Department of Agriculture, Food Survey Research Group; 2006.

26. USDA. Food and Nutrient Database for Dietary Studies, 4.1. A.R.S. Department of Agriculture, Food Survey Research Group; 2010.

27. USDA. Food and Nutrient Database for Dietary Studies, 3.0. A.R.S. Department of Agriculture, Food Survey Research Group; 2008.

28. NCHS, CDC, and USDHHS. National Health and Nutrition Examination Survey Data. Hyattsville, MD: 2009-2010.

29. USDA. A.R.S. Department of Agriculture, Food Survey Research Group. Food and Nutrient Database for Dietary Studies, 4.1. 2012.

30. USDA, ARS, and N.D. Laboratory. USDA National Nutrient Database for Standard Reference, Release 11. 1996.

31. USDA, ARS, and N.D. Laboratory. USDA National Nutrient Database for Standard Reference, Release 18. 2005. 
32. USDA, ARS, and N.D. Laboratory. USDA National Nutrient Database for Standard Reference, Release 20. 2007.

33. USDA, ARS, and N.D. Laboratory. USDA National Nutrient Database for Standard Reference, Release 22. 2009.

34. Centers for Disease Control and Prevention. Trends in Intake of ENergy and Macronutrients-United States, 1971-2000. Morbidity and Mortality Weekly Report. 2004; 53(4):80-82. [PubMed: 14762332]

35. Lasater G, Piernas C, Popkin BM. Beverage patterns and trends among school-aged children in the US, 1989-2008. Nutr J. 2011; 10:103. [PubMed: 21962086]

36. Welsh JA, et al. Consumption of added sugars is decreasing in the United States. Am J Clin Nutr. 2011; 94(3):726-34. [PubMed: 21753067]

37. Turner L, Chaloupka FJ. Encouraging trends in student access to competitive beverages in US public elementary schools, 2006-2007 to 2010-2011. Arch Pediatr Adolesc Med. 2012; 166(7): 673-5. [PubMed: 22751890]

38. USDA and USDHHS. Dietary Guidelines for Americans 2010. U.S. Government Printing Office; Washington, DC: 2010.

39. Monteiro CA, Gomes FS, Cannon G. The snack attack. Am J Public Health. 2010; 100(6):975-81. [PubMed: 20395566]

40. WHO. Global strategy on diet, physical activity and health. Geneva, Switzerland: 2004.

41. Stanley WC, Shah KB, Essop MF. Does junk food lead to heart failure? Importance of dietary macronutrient composition in hypertension. Hypertension. 2009; 54(6):1209-10. [PubMed: 19841293]

42. Reedy J, Susan Krebs-Smith. Dietary Sources of Energy, Solid Fats, and Added Sugars among Children and Adolescents in the United States. Journal of the American Dietetic Association. 2010; 110(10):1477-1484. [PubMed: 20869486]

43. Moshfegh AJ, et al. The US Department of Agriculture Automated Multiple-Pass Method reduces bias in the collection of energy intakes. Am J Clin Nutr. 2008; 88(2):324-32. [PubMed: 18689367]

44. Burrows TL, Martin RJ, Collins CE. A systematic review of the validity of dietary assessment methods in children when compared with the method of doubly labeled water. J Am Diet Assoc. 2010; 110(10):1501-10. [PubMed: 20869489]

45. Livingstone MB, Robson PJ, Wallace JM. Issues in dietary intake assessment of children and adolescents. Br J Nutr. 2004; 92(Suppl 2):S213-22. [PubMed: 15522159]

46. Bandini LG, et al. Validity of reported energy intake in preadolescent girls. Am J Clin Nutr. 1997; 65(4 Suppl):1138S-1141S. [PubMed: 9094910]

47. Bandini LG, et al. Longitudinal changes in the accuracy of reported energy intake in girls 10-15 y of age. Am J Clin Nutr. 2003; 78(3):480-4. [PubMed: 12936932]

48. Bandini LG, et al. Validity of reported energy intake in obese and nonobese adolescents. Am J Clin Nutr. 1990; 52(3):421-5. [PubMed: 2393004]

49. Schoeller DA. Limitations in the assessment of dietary energy intake by self-report. Metabolism. 1995; 44(2 Suppl 2):18-22. [PubMed: 7869932]

50. Heitmann BL, Lissner L, Osler M. Do we eat less fat, or just report so? International journal of obesity and related metabolic disorders: journal of the International Association for the Study of Obesity. 2000; 24(4):435-42.

51. Ng, SW.; Guilkey, David; Popkin, Barry M. How do recessions affect the caloric and volume purchases of Consumer Packaged foods and beverages in the US?. University of North Carolina; Chapel Hill: 2012. 


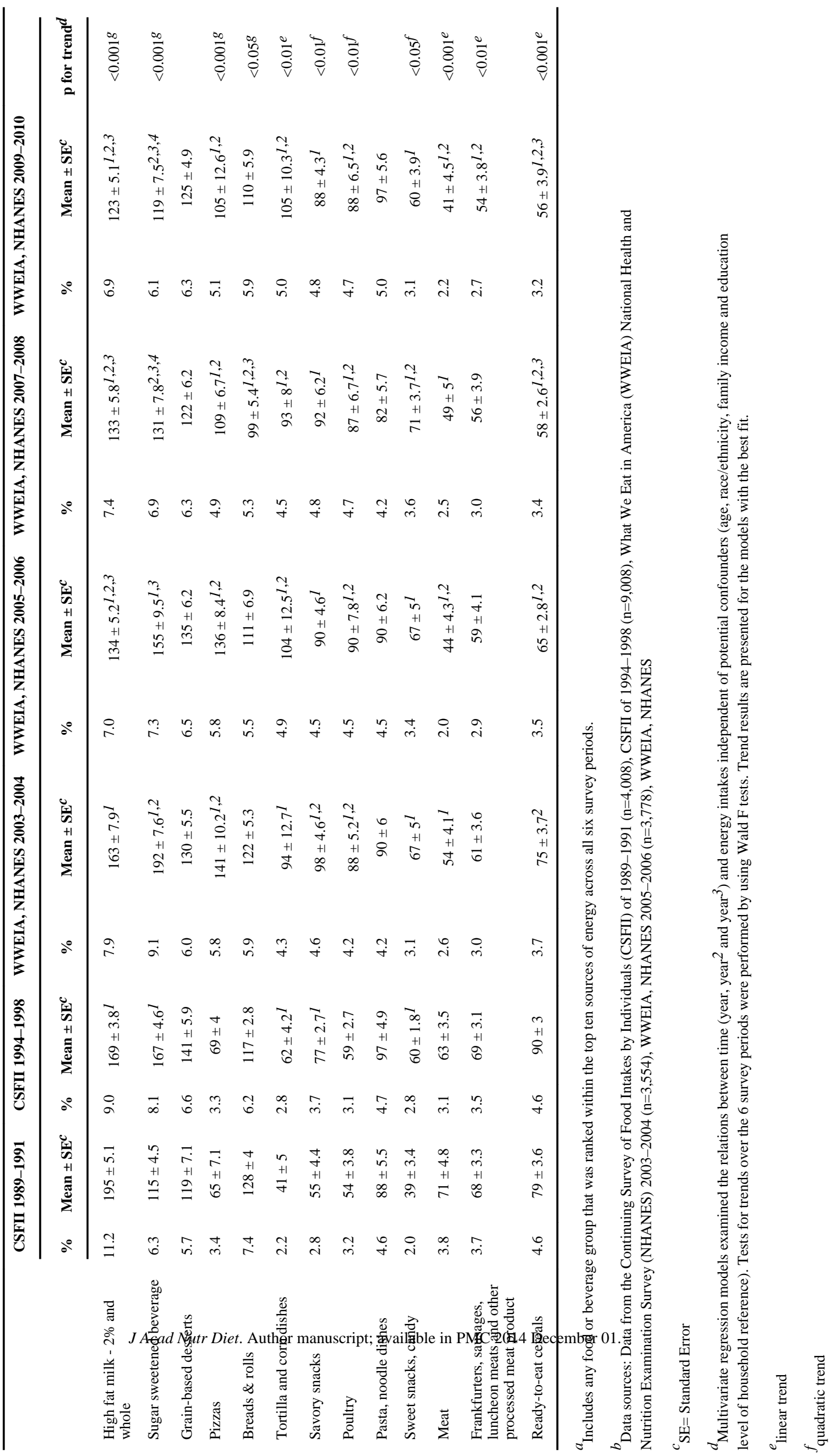




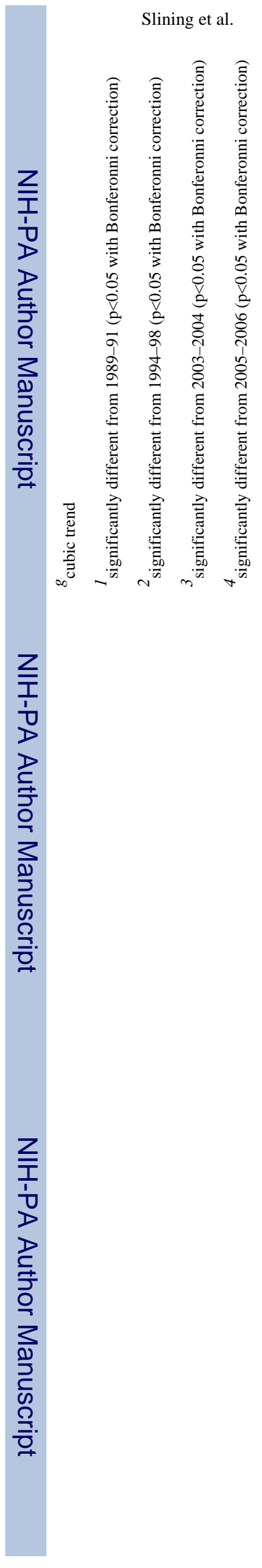

Page 13

J Acad Nutr Diet. Author manuscript; available in PMC 2014 December 01. 